\title{
Ultra nano-hardness of surface layer of irradiated high-density polyethylene (HDPE)
}

\author{
David Manas $^{1, \mathrm{a}}$, Jozef Dobransky ${ }^{2}$ and Lenka Chvatalova ${ }^{1}$ \\ ${ }^{1}$ Tomas Bata University in Zlin, Nam. T.G.Masaryka 5555, Zlin, 760 01, Czech Republic \\ ${ }^{2}$ Technical University of Košice, Faculty of Manufacturing Technologies with a seat in Prešov, Department of Automobile and \\ Manufacturing Technologies, Štúrova 31, 08001 Prešov, Slovakia
}

\begin{abstract}
Using high doses of beta radiation for high-density polyethylene (HDPE) and its influence on the changes of micromechanical properties of surface layer has not been studied in detail so far. The specimens of high-density polyethylene (HDPE) were made by injection moulding technology and irradiated by high doses of beta radiation $(0,33,66$ and $99 \mathrm{kGy})$. The changes in the microstructure and micromechanical properties of surface layer were evaluated using WAXS and instrumented ultra nano-hardness test. The results of the measurements showed considerable decrease in micromechanical properties (indentation hardness, indentation elastic modulus) when low doses of beta radiation are used.
\end{abstract}

\section{Introduction}

Polyethylene is a thermoplastic consisting of crystalline domains and amorphous domains. A thermoplastic can be melted and reshaped as desired by heating it to a temperature above the melting point of the plastic crystalline domains. Crosslinking by aid of radiation or chemically results in the formation of crosslinks or bridges between the macromolecular chains. When this material is heated to a temperature above the crystalline melting point, it does not melt and flow; but exhibits a viscoelastic behaviour. The stretching or deformation of the polyethylene in this condition results in the orientation of the macromolecular chains, and elastic stress is developed in the material. If the polymer is cooled in this stretched condition, reformation of the plastic crystalline domains freezes the elastic stress in the material. The material retains the expanded shape, even on removal of the deforming force. This material is now heat shrinkable, and the stored stress can be recovered at any time by heating it to a temperature above the crystalline melting point. During the application, the heating results in the melting of the plastic crystalline domains, and the stored elastic stress is recovered [1,2]. On the other hand, the process of fabricating heat shrinkable products is based on the shape memory phenomenon.

This phenomenon occurs to some extent in nonprocessed thermoplastics, but its full advantage comes true in the crosslinked thermoplastics, such as the crosslinked polyethylene and its copolymers. Semicrystalline polymers such as low-density polyethylene (LDPE), high-density polyethylene (HDPE) and like other polyolefins, are common heat shrinkable polymers widely used in industry. Heat shrinkable polymers have a wide application in the packaging industry, electrical power and electronic equipment, cable industry and in the preparation of heat shrinkable tubes and connections [3-6]. Typical uses include primary electrical insulation, cable jacketing and repair, strain relief, component encapsulation and water proofing and corrosion protection [6]. In heat shrinkable products usually a hot melt adhesive as a binder is applied underneath to melt over and seal the part (e.g. cable)shortly before shrinking of polymeric cover takes place. For this reason the processing parameters should beoptimised at temperatures higher than the melting temperature of the hot melt adhesive (about 70-90 ${ }^{\circ} \mathrm{C}$ ) [3]. Therefore it is desirable to increase the shrink temperature to as high as possible. The shrinkage is usually measured by placing the specimens in an oil/water bath or a hot air oven at a constant temperature. On the other hand, thermal mechanical analysis (TMA) is the most popular technique to obtain the thermal shrinkage under a constant heating rate. TMA is often used to study the shrinkage mechanisms and shrinkage modelling as well $[7,8]$.

The principle of the radiation process is the ability of the high energy radiation to produce reactive cationts, anoints and free radicals in the material. The industrial application of the radiation process (Figure 1) on polymer and composites includes polymerization, crosslinklinking and degradation. The radiation process involves mainly the use of either electron beam from electron accelerators or gamma radiation from Cobalt - 60 sources.

\footnotetext{
$\bar{a}$ Corresponding author: dmanas@ft.utb.cz
} 


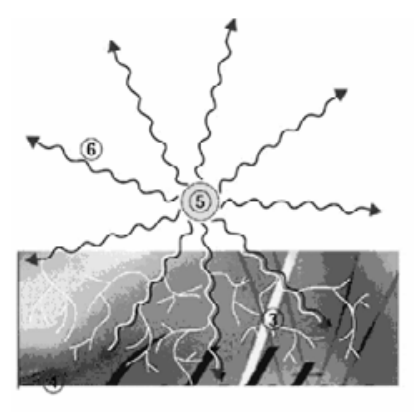

a)

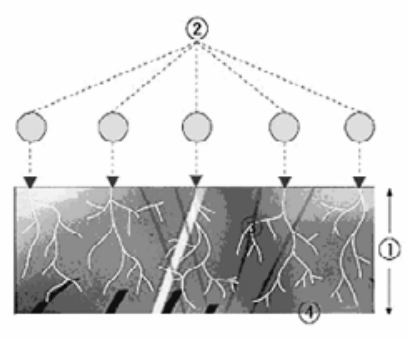

b)
Fig. 1. Design of Gamma rays (a) and Electron rays (b). a) 3 - secondary electrons, 4 - irradiated material, 5 encapsulated $\mathrm{Co}-60$ radiation source, 6 - Gamma rays b) 1 - penetration depth of electron, 2 - primary electron, 3 secondary electron, 4 - irradiated materiál

The aim of this paper is to study the effect of ionizing radiation with different doses, on ultra nano-hardness of surface layer of high-density polyethylene (HDPE) and compare these results with those of non-irradiated samples. The study is carried out due to the ever-growing employment of this type of polymer high-density polyethylene (HDPE) [3-20].

\section{Experimental}

\subsection{Material and methods}

For this experiment High Density Polyethylene (HDPE) DOW - HDPE 25055E, DOW - Chemical company, USA (unfilled, HDPE) was used. Irradiation was carried out in the company BGS Beta Gamma Service GmbH \& $\mathrm{Co}, \mathrm{KG}$, Germany with the electron rays, electron energy $10 \mathrm{MeV}$, doses minimum of $0,33,66$ and $99 \mathrm{kGy}$ on air the ambient temperature.

The samples (Figure 2) were made using the injection molding technology on the injection moulding machine Arburg Allrounder 420C. Processing temperature 245$295{ }^{\circ} \mathrm{C}$, mold temperature $85^{\circ} \mathrm{C}$, injection pressure 80 $\mathrm{MPa}$, injection rate $45 \mathrm{~mm} / \mathrm{s}$. [7-29]

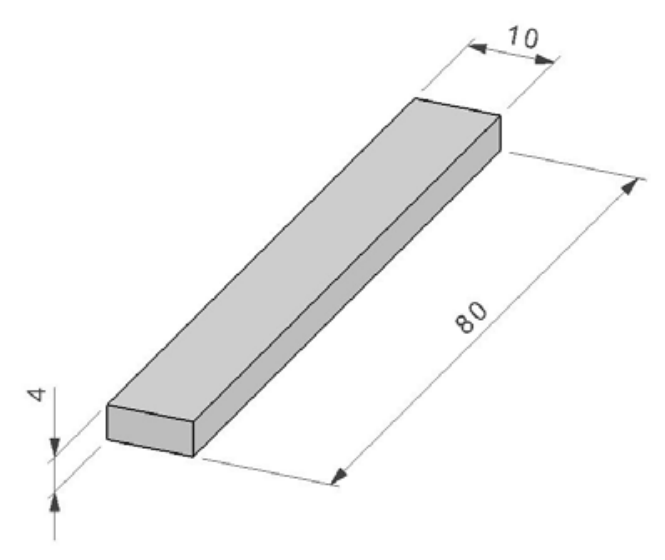

Fig. 2. Dimension of sample.

\subsection{Ultra nano-hardness test}

Nano-indentation test was done using a Ultra Nanoindenation Tester (UNHT) (Fig. 5), CSM Instruments (Switzerland) according to the CSN EN ISO 14577. Load and unload speed was $1000 \mathrm{~N} / \mathrm{min}$. After a holding time of $90 \mathrm{~s}$ at maximum load $500 \mathrm{~N}$ the specimens were unloaded. The specimens were glued on metallic sample holders (Fig. 2). [7-29]

$$
\mathrm{H}_{\mathrm{IT}}=\mathrm{F}_{\max /} \mathrm{A}_{\mathrm{p}}
$$

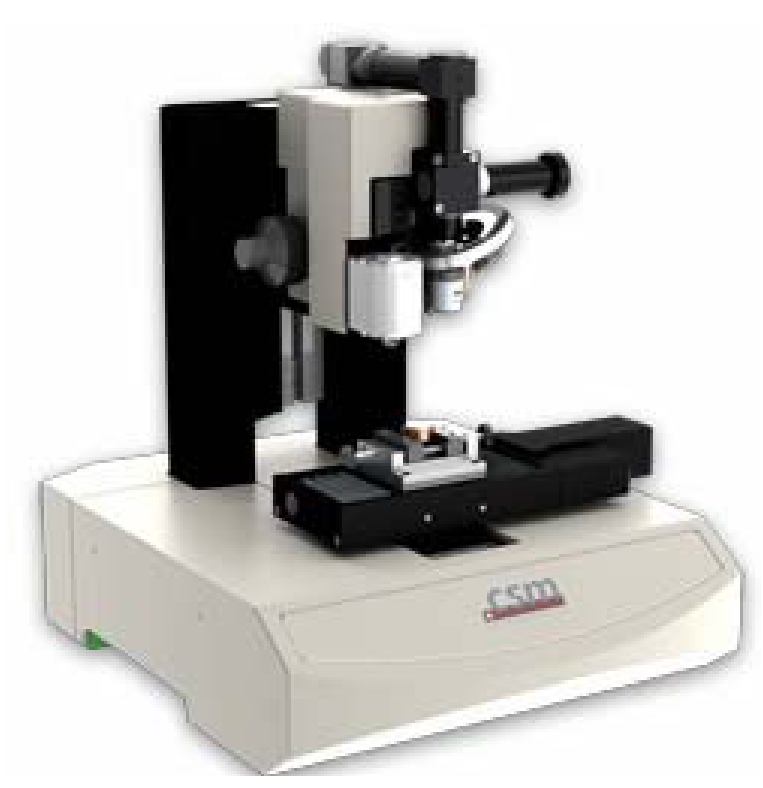

Fig. 3. Ultra Nano-indentation tester. 


\subsection{Wide-angle X-ray scattering}

Wide-angle X-ray diffraction patterns were obtained using a PANalytical X'Pert PRO X-ray diffraction system (Netherlands). The $\mathrm{CuK} \alpha$ radiation was Nifiltered. The scans $\left(4.5^{\circ} 2 \Theta / \mathrm{min}\right)$ in the reflection mode were taken in the range $5-30 \circ 2 \Theta$. The sample crystallinity $(\mathrm{X})$ was calculated from the ratio of the crystal diffraction peaks and the total scattering areas. Crystall size L100 of $\alpha$ most intensive peak at 100 was calculated using Scherrer equation. As a standard "perfect" crystal terephthalic acid with the peak at $2 \Theta=$ $17.4^{\circ}$ and the half maximum breadth $0.3^{\circ} 2 \Theta$ was chosen [7-29].

\subsection{Gel Content}

Gel test is done to find the content of non-filtered phase gel of the given material according to standard CSN EN 579. The portion of $1 \mathrm{~g}$ (of material radiated by low radiation doses) weighed with a precision of three decimal places was mixed with 100-250 ml of solvent. Xylol was used for polypropylene because it dissolves the amorphous part of HDPE, the crosslinking part does not dissolve. The mixture was extracted for 6 hours. Then solutes were separated by distillation. After removing the residual Xylol the crosslinked extract was rinsed by distilled water. The rinsed extract was dried for $6-8$ hours in vacuum at $100^{\circ} \mathrm{C}$. The dried and cooled residue was weighed again with precision to three decimal places and compared to the original weight of the portion. The result is stated in percentage as the degree of crosslinking.

$$
\mathrm{G}_{\mathrm{I}}=[(\mathrm{m} 3-\mathrm{m} 1) /(\mathrm{m} 2-\mathrm{m} 1)]^{*} 100
$$

Where,

$G_{i}$ is the degree of crosslinking of each specimen expressed in percentage

$\mathrm{m}_{1}$ is the weight of the cage and lid in milligrams

$\mathrm{m}_{2}$ is the total of weights of the original specimen, cage and lid in milligrams

$m_{3}$ is the total of the weights of the residue of specimen, cage and lid in milligrams

The result of $G_{i}$ is rounded to the nearest whole number $[9,14]$.

\section{Results and discussion}

The development of micromechanical properties of irradiated high density polyethylene (HDPE) was characterized by the instrumented test of ultra nanohardness $\left(\mathrm{H}_{\mathrm{IT}}\right)$, as can be seen in Figure 4. The lowest values $(39 \mathrm{MPa})$ of indentation hardness were found on high density polyethylene (HDPE) irradiated with radiation dose of $66 \mathrm{kGy}$ radiation dose, while the highest value of indentation hardness were found on non- irradiated high density polyethylene $(54 \mathrm{MPa})$. The decrease of indentation hardness at $165 \mathrm{kGy}$ radiation dose was by $17 \%$ compared to the non-irradiated high density polyethylene (HDPE).

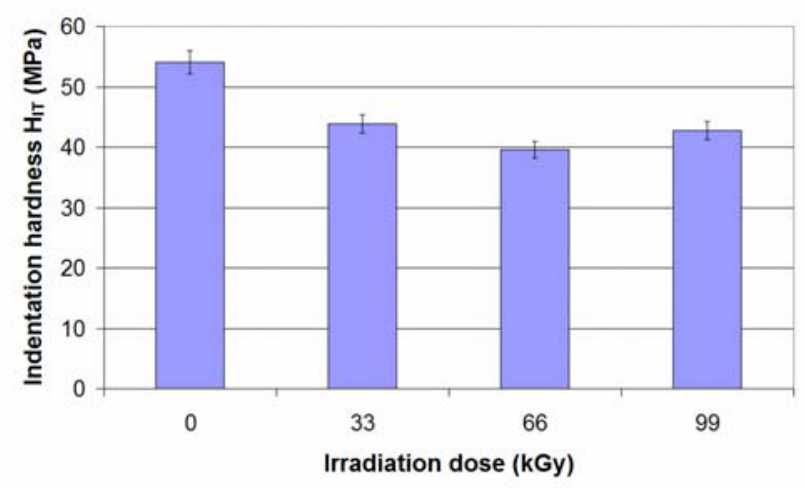

Fig. 4. Indentation hardness $H_{I T}$ vs. irradiation doses.

Similar development was recorded for microstiffness of specimens represented by the indentation elastic modulus $\left(\mathrm{E}_{\mathrm{IT}}\right)$ illustrated in Figure 5. The results of measurements show clearly that the lowest values of indentation elastic modulus were measured on the high density polyethylene (HDPE) (1.04 GPa) irradiated with radiation dose of $66 \mathrm{kGy}$, while the highest values were found on non- high density polyethylene (HDPE) (1.30 $\mathrm{GPa}$. A significant decrease of indentation elastic modulus (11\%) was recorded at the radiation dose of 66 kGy compared to the high density polyethylene (HDPE).

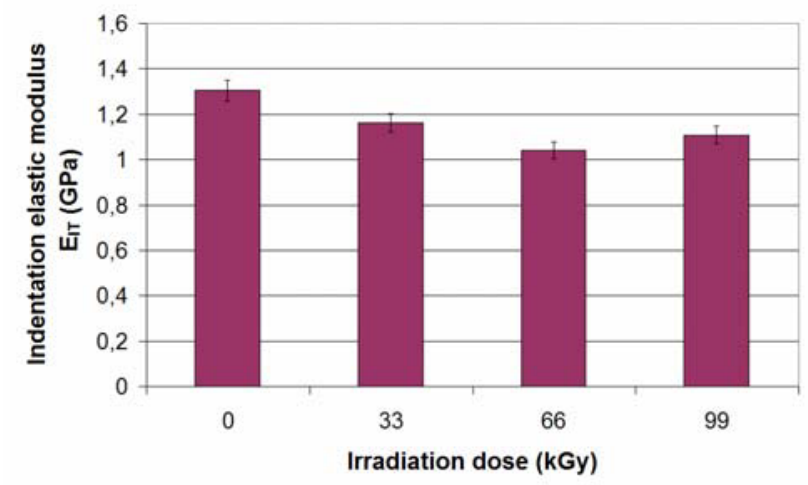

Fig. 5. Indentation elastic modulus $\mathrm{E}_{\mathrm{IT}} \mathrm{vs.}$ irradiation doses.

Other important material parameters obtained during the micro-hardness test were elastic and plastic deformation work. The mechanical work $\mathrm{W}_{\text {total }} 1$ induced by the indentation is only partly consumed as plastic deformation work $\mathrm{W}_{\text {plast }}$. During the removal of the test force the remaining part is set free as work of the elastic reverse deformation $\mathrm{W}_{\text {elast }}$.

Very important values were found for indentation creep. For materials which creeps as polymers, a basic calculation of that creep can be measure during a pause at the maximum force. The creep is the relative change of the indentation depth when the test force is kept constant measured by instrumented test of ultra nanohardness showed (Figure 6) that the highest creep values were 
measured irradiated by $33 \mathrm{kGy}$ dose $(27 \%)$, while the lowest creep value was found in high density polyethylene (HDPE) irradiated by $99 \mathrm{kGy}$ dose (16\%). The creep increase by $27 \%$ as a result of radiation, which represents a considerable decrease of surface layer resistance.

When applying $\beta$-radiation the structure of polypropylene undergoes loss and then a grow of the crystalline phase. It can be assumed that the size of individual crystals will correspond with the loss of crystalline phase (crystalline value $\mathrm{X}$ calculated lay in the range $38-47 \%$ ). Cross-linking occurs in the remaining noncrystalline part which has a significant influence on the mechanical properties of the surface layer. The greatest size (Table 1) of crystalline phase $(47 \%)$ was found at non-irradiated high density polyethylene (HDPE). The lowest size of crystalline phase was found in the case at the radiation dose of $66 \mathrm{kGy}(38 \%)$. On the contrary the smaller size of crystalline phase of high density polyethylene (HDPE) was measured at radiation dose of $99 \mathrm{kGy}(38 \%)$. Its influence on the mechanical behavior is insignificant.

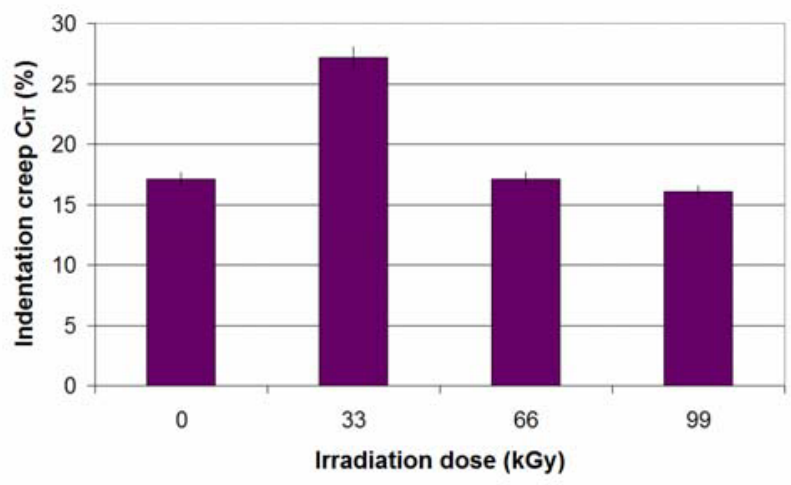

Fig. 6. Indentation creep $C_{I T}$ vs. irradiation doses.

The highest values of plastic deformation work were obtained for non-irradiated high density polyethylene (HDPE). The highest values of elastic deformation work were obtained for high density polyethylene (HDPE) irradiated with radiation dose of $33 \mathrm{kGy}$. The lowest values of $\mathrm{W}_{\mathrm{el}}, \mathrm{W}_{\mathrm{pl}}$ were obtained for high density polyethylene (HDPE) irradiated with dose of $0 \mathrm{kGy}$. Radiation of specimens caused lower values of plastic deformation work which is in Figure 7.

Table 1. X-ray diffraction of non-irradiated and irradiated HDPE

\begin{tabular}{|c|c|}
\hline Sample & X X-ray, $\%, \pm 1 \%$ \\
\hline $0 \mathrm{kGy}$ & 47 \\
\hline $33 \mathrm{kGy}$ & 42 \\
\hline $66 \mathrm{kGy}$ & 38 \\
\hline $99 \mathrm{KGy}$ & 40 \\
\hline
\end{tabular}

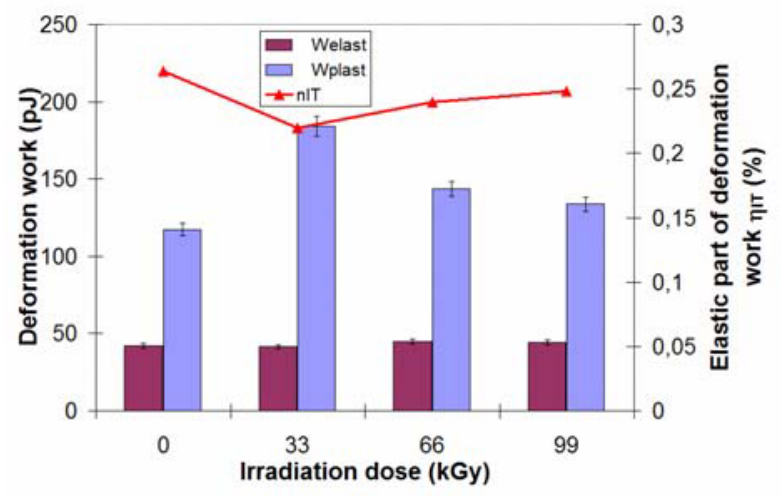

Fig. 7. Deformation work vs. irradiation dose.

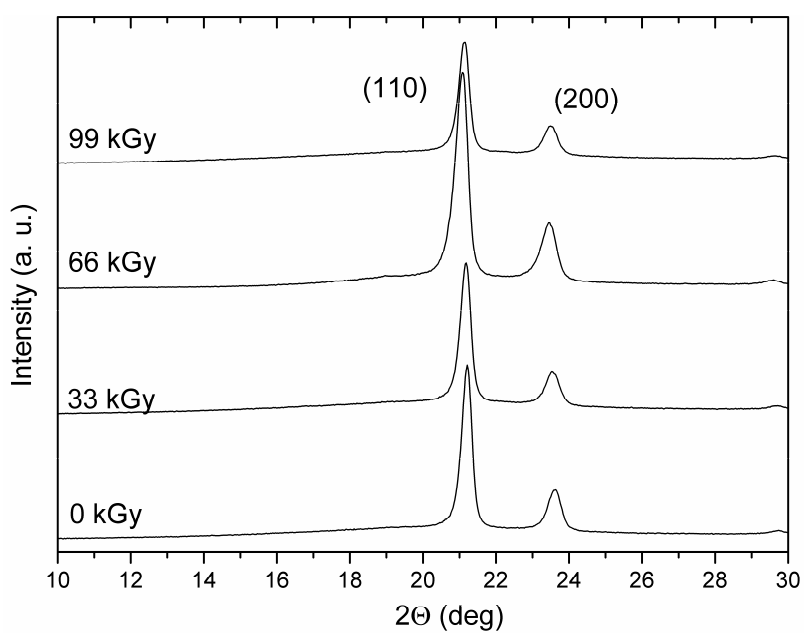

Fig. 8. X- ray diffraction non-irradiated and irradiated PBT.

The figure 8 shows typical X-ray diffraction spectrum of the non-irradiated and irradiated high density polyethylene (HDPE). There is an apparent presence of $\alpha$-phase in the non-irradiated specimen. The greatest grow of $\alpha$-phase is seen at the radiation dose of $66 \mathrm{kGy}$ (Figure 5).

Table 2. Gel content of HDPE vs. irradiation doses.

\begin{tabular}{|c|c|c|}
\hline Sample & Gi (\%) & Std. Dev. \\
\hline $0 \mathrm{kGy}$ & 0 & 0 \\
\hline $33 \mathrm{kGy}$ & 0 & 0 \\
\hline $66 \mathrm{kGy}$ & 0 & 0 \\
\hline $99 \mathrm{KGy}$ & 55 & 2.1 \\
\hline
\end{tabular}

Gel content showed the highest values at radiation dose of $99 \mathrm{kGy}$ at which it reached $55 \%$ degree of crosslinking. Specimens irradiated by $0,33,66 \mathrm{kGy}$ radiation dose showed very similar value $60 \%$ degree of crosslinking (Table 1). 


\section{Conclusion}

The experimental study deals with the effect of modification of the surface layer by irradiation crosslinking on the properties of the surface layer of high density polyethylene (HDPE). High density polyethylene (HDPE) was modified by beta irradiation at doses of 0 , 33, 66, $99 \mathrm{kGy}$. The changes of micromechanical properties were found at the radiation dose of $66 \mathrm{kGy}$ for indentation hardness, indentation elastic modulus (which decreased by $17 \%$ and $11 \%$ ) compared to the nonirradiated high density polyethylene (HDPE).

\section{Acknowledgment}

This paper is supported by the internal grant of TBU in Zlin No. IGA/FT/2017/010 funded from the resources of specific university research and by the Ministry of Education, Youth and Sports of the Czech Republic within the National Sustainability Programme project No. LO1303 (MSMT-7778/2014) and also by the European Regional Development Fund under the project CEBIATech No. CZ.1.05/2.1.00/03.0089. Special thanks also to Dr. Michal Danek (BGS Beta Gamma Service GmbH \& $\mathrm{Co}, \mathrm{KG}$, Germany) for his kind assistance during sample preparation.

\section{References}

1. Dj. Gheysari, Eur. Polym. J. 37 (2001) 295-302, (2001)

2. K. Makuuchi, S. Cheng. Wiley, Hoboken, 2011.

3. J.G. Drobny, Elsevier, Oxford, 2013.

4. D. Dobrotə, Energy Procedia, 100, 1160-1166, (2015)

5. G. Zamfirova, V. Gaydarov, T. Zaharescu, L. G. Silva. Chemicke Listy, 104, 283-286, (2010)

6. D. Manas, M. Hribova, M. Manas, M. Ovsik,M. Stanek, Thin Solid Films, 530, 49-52,(2013)

7. O. Uzuna, U. Kölemena, S. Çelebi, N. Güçlü, Journal of the European Ceramic Society. 25, 969977, (2005).

8. W. C. Oliver, G. M. Pharr. J Mater Res, 7. (6) 1564-1583, (1992)

9. E. Ragan, P. Baron, J. Dobránsky. Advanced Materials Research 383-390, 2813-2818, (2012).

10. H. Wang, L. Xu, R. Li, J. Hu, M. Wang, G. Wu, Radiation Physics and Chemistry, 125, 41-49, (2016)

11. J. Dobránsky, L. Běhálek, P. Baron, Key Engineering Materials, 669, 36-43, (2016)

12. Dobransky, J., Běhalek, L., Baron, P., Kočiško, M., Simkulet, V., Vojnova, E., Briančin, J. Metalurgija, 55 (3), pp. 449-452, (2016)

13. Dobránsky, J., Kočiško, M., Baron, P., Simkulet, V., Běhálek, L., Vojnová, E., Nováková Marcinčinová, L. Metalurgija, 55 (3), pp. 477-480, (2016)

14. J. Čop, L. Fojtl, O. Bílek, V. Pata, Manufacturing Technology, 16 (2), pp. 334-338, (2016)
15. Singh, P. Kishore, M. Singh, A. Srivastava, Radiation Effects and Defects in Solids, 170 (10), 845-853, (2015)

16. S. Kashyap, D. Datta, International Journal of Plastics Technology, 19 (1), 1-18, (2015)

17. S. Zhang, R. Dubay, M. Charest, Expert Systems with Applications, 42 (6), 2919-2927, (2015)

18. S. Ota, Radiat Phys Chem 1981;18(1-2):81-7.

19. S. Kumar, MV. Pandya, JAppl Polym Sci 1997;64:823-9.

20. JW. Hoffman, IEEE Electr Insulat Mag 1991;7(3):16-23.

21. R. Rado, P. Zelenak, Int Polym Sci Technol 1992;19(4):72-7.

22. KS. Wayne, Polym Eng Sci 1994;34(14):1121-8.

23. JW. Hoffman, IEEE Electr Insulat Mag 1991;7(2):33-8.

24. H. Kambe, T. Kato, JAppl Polym Sym 1973;20:365-75.

25. H. Kambe, T. Kato, M. Kochi, JMacromo 1 SciChem 1974;A8(1):157-64.

26. PK. Patra, CK. Das, JPolym Eng 1997;17(3):23144.

27. JK. Mishra, S. Raychowdhury, CK. Das, Polym Int 2000;49:1615-23.

28. JK. Mishra, CK. Das, J Elastom Plast 2001;33:13753.

29. SR. Chowdhury, JK. Mishra, CK. Das, Macromol Mater. Eng 2001;286(4):243-7. 